\title{
Y el viaje continúa: primer año de la nueva época de la $R D U$
}

\author{
Magda Campillo Labrandero y \\ Samuel Arroyo Nava
}

Magda Campillo Labrandero

mcl@unam.mx

Licenciada, Maestra y Doctora en psicología educativa. Docente de educación superior y posgrado. Obtuvo la beca Fullbright-García Robles para estudiar el doctorado en la Universidad de la Ciudad de Nueva York, (CUNY) donde se especializó en cuestiones de autorregulación y evaluación educativa. Por más de 10 años estuvo como subdirectora del área de Trayectoria Escolar en la Dirección General de Evaluación Educativa trabajando temas vinculados al abandono y rezago escolar. Actualmente está a cargo de la Subdirección de Investigación en Educación de la Coordinación de Desarrollo Educativo e Innovación Curricular.

\section{Samuel Arroyo Nava}

rdu.samuel@gmail.com

Universidad Nacional Autónoma de México. Coordinadora de Investigación en Educación, Coordinación de Desarrollo Educativo e Innovación Curricular. Licenciado en Lengua y Literaturas Hispánicas por la UNAM y maestro en Diseño y Producción Editorial por la UAM-Xochimilco. Actualmente funge como editor de la Revista Digital Universitaria. 
Revista Digital Universitaria

Vol. 19, Núm. 4, julio-agosto 2018

El número de julio-agosto de la RDU llega justo al año de que iniciamos la nueva época, en un periodo de transición gubernamental de gran trascendencia para el país que da fin a un largo proceso electoral y durante uno de los eventos deportivos de futbol más importantes a nivel internacional. En este contexto presentamos a ustedes, amables lectores, esta edición de la RDU, con la seguridad que la disfrutarán tanto como nosotros.

La sección de Varietas se compone de cuatro artículos que giran en torno a diferentes facetas de la actividad científica. En "Heterociclos: pequeñas y maravillosas estructuras en el organismo humano" Delia Hernández, Oscar García, Raúl Colorado y Esmeralda Sánchez, nos describen el fascinante mundo de estos compuestos químicos, así como algunas estructuras fundamentales de nuestro organismo en las que se encuentran estos diminutos anillos. Aunque todos sabemos que la química y la farmacéutica guardan una relación cercana, en general desconocemos el largo y costoso camino que recorre un medicamento antes de llegar a la estantería de la farmacia. Germán Novoa, en su artículo "El ser humano como conejillo de indias", nos habla de los derechos y las obligaciones de los participantes voluntarios (tanto sanos como enfermos), en los estudios clínicos que se realizan para desarrollar los medicamentos que consumimos hoy en día. El autor nos describe las rigurosas etapas que sigue la industria farmacéutica para el desarrollo de sus investigaciones, así como los principios éticos que debe tener cualquier investigación en la que participen humanos.

En esta época de tecnología y comunicación, la información disponible (sobre prácticamente cualquier tema) puede ser abrumadora; basta hacer una búsqueda en internet para comprobarlo. Eduardo Álvarez y Layla Michán en su texto "La ciencia de la ciencia" nos hablan de la cienciometría, una nueva forma de analizar la gran cantidad de información científica que, gracias al auge digital, crece cada día de manera exponencial. La cienciometría busca analizar la información de la producción científica y a través de métodos que se basan en tomar los artículos científicos, busca tendencias, patrones, relaciones y crea indicadores.

No obstante, la gran cantidad de información que deriva de la investigación científica, reducir la brecha entre el conocimiento original y su aplicación sigue siendo un reto permanente. Flora Hernández y Melchor Sánchez Mendiola en su artículo "Investigación traslacional en educación: Un puente entre teoría y práctica educativa", mencionan que la traslación busca ser un vínculo entre docentes e investigadores para que, con base en la mejor evidencia científica, se puedan diseñar propuestas para la mejora de la educación. El artículo anterior se complementa con el texto de Yazmín Lara, Adriana Olvera y Maura Pompa, "Los docentes como investigadores de su práctica". Las autoras describen un diplomado que ejemplifica una actividad relacionada con la traslación en la educación y rescatan las experiencias de los asistentes; éste se presenta en la sección de Continuum educativo - La voz de los docentes. 
Revista Digital Universitaria

Vol. 19, Núm. 4, julio-agosto 2018

Con el compromiso que caracteriza a la RDU de dar voz a los alumnos, en esta ocasión Montserrat Mendoza, alumna de licenciatura, nos habla del proceso de elegir la carrera de Arquitectura y comparte algunas reflexiones sobre la belleza arquitectónica del campus de Ciudad Universitaria.

Pese a la época tan complicada que vive nuestro país, Gonzalo Soltero en su artículo "¿Cuánto vale tu felicidad?" nos cambia la jugada en la sección Universidades y nos presenta un panorama alentador ya que los mexicanos reportan, en encuestas nacionales e internacionales, los puntajes más altos de felicidad y satisfacción de vida (bienestar subjetivo) y resulta que uno de los mayores satisfactores consiste en ser estudiante; las estadísticas indican que la educación es un ingrediente importante para la felicidad humana.

Por último, en el marco de la Copa Mundial de Fútbol Rusia 2018, la sección de Caleidoscopio se compone de una infografía que diseñaron Maura Pompa y Samuel Arroyo sobre mujeres y hombres futbolistas que han triunfado en las canchas y en la vida universitaria. La alineación de este número se complementa con una Trivoshka con datos interesantes sobre el país sede del mundial, ésta fue elaborada por Maxim Barkov y ella combina el conocimiento de su cultura natal: la rusa, y la aculturación que le dan varios años de residir en México; retamos al lector a contestar las preguntas y divertirse un rato.

Con estas lecturas cerramos el tercer número del año e iniciamos el periodo vacacional en la UNAM. Deseamos a los universitarios un merecido descanso y los invitamos a disfrutar de la RDU. 